\title{
BURUH WANITA PEKERJA “ Fresh Vegetables \& Fruits Agribisnis” di PT RODEO MALANG \\ ( Studi Mikro Analisis Gender \& Metode Proba untuk Mendukung Pengarustamaan Gender)
}

\author{
Ismini $^{1)}$, Wiwin Purnomowati ${ }^{2)}$ \\ Program Studi Agribisnis ${ }^{1)}$ Program Studi Akutansi ${ }^{2)}$ \\ Universitas Widyagama Malang \\ Email : ismini_uwg@yahoo.co.id
}

\begin{abstract}
ABSTRAKS
Ideologi gender yang disosialisasikan oleh masyarakat merupakan system nilai dan norma yang mempengaruhi posisi maupun hubungan wanita dengan pria atau lingkungan. Ikut sertanya wanita kedalam pasar tenaga kerja membawa konsekwensi kepada peran yang memaksa wanita memperpanjang waktu kerja. Jam kerja panjang, beban kerja berat, terkadang pada malam hari serta mitra kerja kaum pria yang menurut sebagian masyarakat adalah kurang sesuai, apalagi wanita yang sudah keluarga. Metode penelitian dengan metode penelitian berperspektif feminis. Penentuan contoh semua responden pekerja wanita di RODEO, selanjutnya dianalisis secara deskripsi dan gender. Hasil penelitian menunjukkan bahwa hampir $100 \%$ responden usia produktif dan hanya ada 1 orang yang berusia diatas 40 tahun inipun bagian yang memasak untuk menyiapkan makanan para pekerja. untuk tingkat pendidikan sebagian besar minimal SLTA. Hasil analisis gender bahwa wanita mencurahkan waktunya untuk kerja produktif dan juga bekerja dimalam hari karena memang jenis pekerjaan harus dilakukan dimalam hari juga sebab pagi mulai jam 03.00 komoditi sayur dan buah harus segera dikirim dibeberapa pulau lewat ekspedisi juga lewat udara /pesawat terbang. Namun pemberi kerja tidak memaksa untuk bekerja malam hari tetapi konsekwensinya harus siap bekerja jika sudah bersedia bekerja di Rodeo.
\end{abstract}

\begin{abstract}
Gender ideology promoted by society is a system of values and norms that influence the position and relationship of women to men or the environment. The participation of women into the labor market has consequences for the role that forces women to extend the working time. Long working hours, heavy workload, sometimes at night as well as partners of men who according to some people is not appropriate, especially women who have a family. Research methods research methods feminist perspective. Determination example all respondents female workers in RODEO, then analyzed the description and gender. The results showed that almost $100 \%$ of respondents age and there is only one person aged over 40 years even this part of the cooking for meniapkan food workers. to the level of the majority of at least high school education. The results of gender analysis that women devote his time remedy productive work and also work at night because it is the type of work to be done at night also cause morning starting at 3:00 commodity vegetables and fruit should be immediately sent several expeditions also pilau passing through the air / aircraft. But employers are not forced to work night but the consequences have to be ready to work if it is willing to work in Rodeo.
\end{abstract}

Keywords: Women, Women Workers, Women workers Rodeo Malang. 
PENDAHULUAN

Potensi wanita perlu di kembangkan dalam pembangunan di negara sedang berkembang. Di dalam masyarakat, meskipun peran wanita dan pria sangat penting, namun dalam berbagai kategori sosial dan ekonomi, wanita kurang beruntung dibandingkan pria. Pengalaman menunjukkan adanya pembagian kerja yang tidak adil, akses dan kontrol terhadap sumber daya ekonomi dan pengambilan keputusan yang masih rendah. Bahkan kadangkala peran mereka di rumah tangga untuk mempertahankan pangan dan mata pencaharian juga tidak dianggap penting. Dari berbagai pengalaman pembangunan di negara berkembang, mereka sumber daya manusia, wanita merupakan kelompok yang kurang beruntung. Pada umumnya mengalami marginalisasi baik di bidang politik, ekonomi, pengetahuan dan sosial. Peran wanita dalam pembangunan, termasuk pembangunan pertanian kurang nampak diperhatikan termasuk yang terjadi di Indonesia, meskipun lebih dari 60 persen kegiatan pertanian dilakukan oleh wanita. Diharapkan peran wanita dan pria dalam pembangunan dilihat sama pentingnya sehingga akan terjadi efisiensi, kesetaraan dan sustainabilitas sehingga tercapai kemandirian masyarakat dan dapat dievaluasi apabila setiap kebijakan dari sektormasih harus melalui perjuangan.
Dalam upaya mengurangi kesenjangan gender yang pada gilirannya menimbulkan permasalahan gender. Agar mencapai keadilan kesetaraan gender (KKG) maka diperlukan pengarustamaan gender (PUG) yang merupakan suatu strategi untuk mencapai kesataraan dan keadilan gender melalui kebijakan dan program yang memperhatikan pengalaman, aspirasi, kebutuhan dan permasalahan wanita dan pria dengan memperhatikan akses kepada partisipasi dalam, mempunyai kontrol atas, dan memperoleh manfaat yang sama dari hasil pembangunan (http://www.mnegpp.go.id/=kesetaraan, 2009)

Permasalahan yang dihadapi oleh wanita pekerja sangat komplek, berkaitan dengan gender dan peran ganda wanita sebagai istri dan sekaligus sebagai pencari nafkah yang terperangkap dirumah harus bekerja lebih berat. Penelitian menunjukkan bahwa mereka bekerja lebih panjang. Ada juga beberapa faktor yang berpengaruh terhadap keberhasilan wanita dalam pembangunan antara lain wanita masih cenderung membatasi atau membendung aspirasi dirinya sendiri, sistim nilai budaya yang ada, lapangan pekerjaan wanita masih kurang (Prihantinah, 2006) 
Di Jawa Timur tepatnya di Kabupaten Malang di Rodeo Fresh Vegetables \& Fruits Agribisnis. Di perusahaan ini mempekerjakan wanita sebagai pekerja yang digolongkan pada kegiatan berat/ pekerjaan pria karena jam kerjanya harus pada malam hari dan harus menginap di perusahaan tempat bekerja, jam kerja dimulai jam 15.00 03.00 dini hari. Sebenarnya wanita tidak cocok terlibat pada pekerjaan tersebut apabila mengacu pada budaya gender yang berkembang di masyarakat pada umumnya, pekerjaan mengandalkan kekuatan fisik. Oleh karena itu bukan digolongkan pekerjaan wanita yang menurut stereotipe digambarkan sebagai makhluk yang lemah. Kenyataan yang ada adalah sebagai wanita pekerja di Perusahaan ini dilakukan oleh wanita, padahal sebagai wanita pekerja di Perusahaan Rodeo ini fisik harus kuat, karena harus bekerja pada malam hari dan harus menginap di tempat kerja.

Penelitian bertujuan untuk mengetahui : 1)Profil wanita pekerja sebagai pekerja Fresh Vegetables \& Fruits Agribisnis di Rode; 2) Alasan wanita mau bekerja sebagai pekerja Fresh Vegetables \& Fruits Agribisnis yang bekerja pada malam hari mulai jam 15.00 - 03.00 dini hari dan harus menginap di tempat kerja
3) Hubungan gender dengan kerja wanita sebagai pekerja Fresh Vegetables \& Fruits Agribisnis.

Metode penelitian adalah penelitian yang berperspektif gender. Dengan menganalisisi data secara diskriptiif kuantitatif dengan analisis gender.. Diskriptif digunakan untuk mencari gambaran tentang keadaan wanita yang bekerja, Sedangkan secara kuantitaif mencari hubungan antara peran serta wanita dalam pengelolaan lahan pertanian dengan peningkatan produktifitas. Data yang diperlukan meliputi data primer dan data skunder. Data primer diperoleh dari responden dengan teknik wawancara. Sedangkan data skunder dari dokumentasi instasi terkait. Studi Mendalam (Indepth Study),tujuannya adalah untuk mendapatkan data yang lebih mendalam dari beberapa informan kunci (key person) yang telah dipilih setelah survey dilakukan juga kepada pemimpin perusahaan dan tokoh masyarakat. Studi mendalam dilakukan dengan metode partisipatif yaitu mengikuti kegiatan wanita, karena pekerja bekerja pada malam dan harus menginap, maka peneliti juga mengikuti kegiatan wanita juga dilanjut diskusi dirumah responden supaya waktu leluasa . Formulasi masalah dikembangkan melalui suatu pendekatan serta kerja sama secara partisipatori antara peneliti dengan yang 
diteliti, sehingga kepentingan keduanya terpenuhi. Dalam pengumpulan data, saat pengambilan data yang tepat dengan memperhatikan situasi dan kondisi responden adalah sangat menentukan validitas data yang dikumpulkan

Data yang sudah diperoleh selanjutnya dilakukan tabulasi data terpilah kemudian dianalisis dengan Teknik Analisis Model Gender Analisis Pathway (GAP) dan dengan Metode Proba( Metode Gap merupakan metode analisis`untuk mengetahui kesenjangan gender dengan melihat aspek akses,peran, manfaat dan control yang diperoleh laki-laki dan perempuan. Teknik Analisis Model Proba ( Problem Based Approach) atau Analisis "Berbasis masalah “

Analisis gender untuk menganalisis peran pria wanita dalam masyarakat serta mengidentifikasi potensi dan kebutuhan spesifik mereka. Analisis gender merupakan teknik untuk memahami profil kegiatan (aktifitas), yaitu dengan mengenal, mengetahui serta memahami siapa yang melakukan apa, dimana dan bilamana serta perbedaan akses dan control anggota masyarakat (pria dan wanita) terhadap sumberdaya dan siapa mendapatkan manfaat pada suatu kegiatan tertentu, serta dampak akibat dari kegiatan tertentu.

\section{HASIL DAN PEMBAHASAN}

a.Sejarah Singkat Perusahaan.

RODEO mulai didirikan pada tahun 1993. Lokasi di Desa Sumber Wuni, terletak di jalan Sumber Wun dan sekarang di Dusun Karanganyar dengan lokasi yang lebih luas dan cocok serta tepat sekali karena lokasi usaha tersebut berdekatan dengan tersedianya bahan baku yang dibutuhkan.

Usaha ini dirintis oleh Ir. H.M. Maulud, beliau adalah pemilik sekaligus pimpinan perusahaan. Nama " RODEO" berasal dari singkatam nama kedua orang tua pemilik perusahaan. Pada awalnya usaha ini dimulai dengan hanya menyalurkan komoditi jagung manis ke pasar-pasar tradisional di daerah Malang dengan menggunkana sepeda motor. Jaugung manis di pasar tradisional kurang menjanjikan kemudian pemilik usaha beralih menyalurkan jagung manis ke supermarket yaitu Hero Malang.

Seiring berjalanannya waktu dengan banyaknya permintaan pasar dan kebutuhan konsumen, bapak H.M Maulud tidak hanya menyalurkan jagung manis saja, tetapi menyalurkan beberapa komoditi yang banyak dibutuhkan oleh konsumen, penambahan komoditi pada buah seperti jeruk, papaya pisang, bengkoang, sirsak dan lain-lain. Sedangkan pada sayuran seperti Capri, tomat, cabe, bayam merah,kentang, brokoli,kucai, akar 
alang-alang,sawi, mint, paprika, kecambah, wortel, daun mlinjo, daun prey, pare, terong dan lain-lain.

Dengan bertambahnya komoditi yang disalurkan dan semakin banyak permintaan konsumen maka pemilik menambah jumlah pekerja dan menambah bangunan untuk meningkatknan usahanya.

\section{b. Lokasi Perusahaan.}

Lokasi perusahaan RODEO bertempat di Dusun Kalianyar Bedal Lawang Malang, lokasi ini lokasi tempat penambahan pengembangan usaha yang dulu berada di jalan Sumber Wuni no.1. Lokasi di Dusun Kalianyar ini merupakan lokasi yang strategis karena karena sangat menguntungkan karena berdekatan dengan bahan baku buah dan sayur-sayuran.

\section{c. Personalia.}

Jumlah karyawan pada perusahaan ini dulu sebanyak 12 orang dengan latar belakang dan pendidikan juga hari kerja (hari senin sampai sabtu) yang berbeda - beda berlaku di perusahaan penyalur buah dan sayur di RODEO. Semua pekerja yang ada ditempatkan di asrama yang telah disediakan di perusahaan. Adapan jam kerja karyawan di RODEO ini adalah sebagai berikut :

- Bagian Tata Usaha : untuk jam kerja karyawan pada bagian tata usaha setiap hari masuk mulai pukul 07.00
- 17.00 wib dan istirahat pukul 11.45 -13.45 wib,

- Bagian Proses Produksi : Kegiatan untuk bagian proses produksi, mulai dari pembersihan,pengeretan, pengepakan dimulai setelah sayuran dan buah2an datang yaitu sekitar pukul 17.00 wib sampai dengan selesai pengepakan semua barang pesanan sekitar pukul 03.00 wib. Jam kerja pada bagian proses produksi sifatnya fleksibel artinya jika permintaan pelanggan meningkat, maka akan menambah jumlah bahan yang diproses sehingga jumlah jam kerja bertambah pula.

- Bagian Transportasi : Untuk jam kerja pada bagian transportasi dimulai pukul 06.00-12.00 wibuntuk pengiriman di daerah Malang, untuk pengiriman daerah Surabaya di mulai pukul 08.00 sampai dengan selesai sekitar pukul 14.00, sedangkan untuk pengiriman barang ke Bali a, Jakarta< Makasar dan lainnya membutuhkan waktu antara 1-2 hari.

\section{d. Profil Responden}

Penelitian terhadap wanita pekerja di RODEO merupakan penelitian yang berprespektif wanita, merupakan penelitian kajian wanita dengan menggunakan analisis gender untuk mengungkapkan mengapa wanita mau dan mampu menjadi pekerja buruh 
di RODEO. Pemilik RODEO adalah Bapak Ir. H.M. Maulud,. Lokasi perusahaan RODEO bertempat di Dusun Kalianyar Bedal Lawang Malang, lokasi ini lokasi tempat penambahan pengembangan usaha yang dulu berada di jalan Sumber Wuni no.1. Lokasi di Dusun Kalianyar ini merupakan lokasi yang strategis karena karena sangat menguntungkan karena berdekatan dengan bahan baku buah dan sayursayuran.

Pada umumnya hubungan dalam perusahaan dengan pekerja untuk bisa diterima kerja sebagai pekerja tidak memperhitungkan hubungan kekerabatan, namun ditekankan pada perhitungan ekonomis rasional. Pada awal terjadinya hubungan kerja biasanya ada perjanjian misalnya soal gaji, ikatan kerja. Kontinyuitas kerja sangat dibutuhkan oleh pekerja karena kaitannya dengan kontinyutas pendapatan demi memenuhi kebutuhan hidup sehari-hari. Seperti telah diuraikan sebelumnya, bahwa hubungan kerja bersufat symbiose mutualisme yaitu hubungan saling menguntungkan kedua belah pihak, walaupun terjadi hubungan yang asimetris dimana ada kesan eksploitasi terhadap pekerja, namun disisi lain pekerja merasakan suatu keuntungan dilihat dari kelangsungan bekerja. Sedangkan hubungan sesame pekerja baik wanita ataupun kondektur pria menurut semua responden baik. Membantu suami adalah selalu diucapkan oleh wanita sebagai istri , apapun yang dikerjakan dan berapapun penghasilan yang diperoleh suatu kerja produktif. Secara implisit pernyataan tersebut tertangkap adanya internalisasi gender kedalam diri wanita sendiri. Sedangkan wanita yang termotivasi karena kebutuhan social disamping juga ingin mencari pengalaman kerja dan ingin mempunyai banyak teman.

\section{Hasil Analisis Gender. :}

Hasil penelitian menunjukkan bahwa terjadi eksploitasi terhadap wanita dari segi tenaga kerja dan wanita mau dan mampu melakukan pekerjaan yang digolongkan pekerjaan pria, padahal menurut anggapan masyarakat bahwa wanita tidak pantas melakukan pekerjaan yang harus meninggalkan rumah apalagi juga pada malam hari dan hal ini apabila fisik tidak sehat maka bukan tidak mungkin bisa melaksanakan tugas.

\section{1) Akses}

Akses yaitu kesempatan untuk menggunakan sumberdaya tanpa memiliki wewenang untuk mengambil keputusan terhadap cara penggunaan dari hasil sumberdaya tersebut. Dari hasil penelitian menunjukkan, bahwa kegiatan dilakukan oeh wanita yang terlibat sebagai pekerja maka wanita 
mempunyai akses , khusus pada kegiatan sebagai kondektur bus ini, pria/suami tidak mempunyai akses karena memang pekerjaan ini yang bisa masuk dalam pekerjaan ini adalah terikat dengan ketentuan yang berlaku pada innstansi wanita bekerja tidak mudah untuk bisa diterima sebagai tenaga kerja ini. Sementara kegiatan yang menyangkut pembagian diri dari segi kualitas intelektual masih dikuasai pria seperti kesempatan untuk mendapatkan penyuluhan dan ketrampilan.Dalam hal ini wanita sama sekali tidak mempunyai akses.

\section{2) Kontrol}

Kontrol yaitu kewenangan penuh yang dimiliki wanita dan pria untuk pengambilan keputusan. Wanita yang bekerja mempunyai beban ganda yatu disektor publik dan sektor domistik. Dari hasil penelitian menunjukkan, bahwa kegiatan dilakukan oeh wanitas, maka wanita mempunyai akses

\section{3) Manfaat}

Menurut anggapan suami/pria bahwa keterlibatan isteri pada kegiatan mencari nafkah adalah untuk mmbantu suami dan dapat meringankan beban suami. Wanita yang bekerja akan memperoleh penghasilan atau upah. Namun dari segi manfaat yang diperoleh dari upah yang diterimanya ternyata tidak berbeda. Mereka sama sekali tidak memanfaatkan uang dari hasil jerih payahnya untuk kepentingan diri sendiri. Hampir semua responden (100 \%) mengakui bahwa pendapatan yang diperolehnya adalah untuk memenuhi kebutuhan sehari-hari atau kebutuhan rumah tangga

\section{4) Dampak}

Dampak terhadap diri sendiri, wanita yang bekerja mereka adalah sebagai ibu rumah tangga. Oleh karena walaupun mereka terlibat dalam pekerjaan produktif mereka juga harus tetap melaksanakan kewajiban sebagai ibu rumah tangga. Dalam memikul beban ganda tersebut menyebabkan dampak terhadap diri sendiri diantaranya capek-sapek, punggung pegal, pusing, masuk angin dan lain-lain.

Beratnya beban kerja yang dipikul wanita menyebabkan keterbatasan waktu dan energi untuk melakukan kegiatan, yang mengakibatkan dampak terhadap keluarga.

\section{KESIMPULAN DAN SARAN}

\section{Kesimpulan}

1. Profil responden, wanita pekerjaan jam kerja yang panjang sampai malam hari dan seringkali harus menginap ditempat kerja karena pekerjaan harus ada yang dikerjakan dimalam hari

2. Alasan wanita bekerja sebagai kondektur bus mempunyai beberapa alasan semua responden ( $100 \%$ ) mengatakan memenuhi kebutuhan 
ekonomi demi membantu suami,untuk kebutuhan social dan beberapa responden mengatakan untuk mencari pengalaman dan menambah teman

3. Hasil penelitian ditemukan adanya perlawanan terhadap streotipe wanita bahwa waita itu lemah, halus dan sebagainya, ternyata wanita mau dan mampu melakukan pekerjaan sebagai kondektur bus yang menurut pandangan masyarakat pantas dan kuat dilakukan oleh pria. Keadaan wanita pekerja kondektur bus apabila ditinjau dari curahan waktu kerja rumah tangga ditambah kerja namun dianggap membantu. Sementara manfaat wanita bekerja untuk memenuhi kebutuhan rumah tangga. Akses kontrol mengikuti kegiatan masyarakat juga kurang, namun tetap melakukan tanggung jawab terhadap keluarga.

\section{Saran}

1. Perlu berpartisipasi dalam Lokakarya, Seminar, pelatihan dan lain-lain yang menghadirkan penentu kebijakan untuk mengangkat harkat dan martabat wanita.

2. Untuk memperkuat bargaining power wanita pekerja, maka perlu dilakukan action research untuk menemukan model-model pembinaan wanita.

\section{DAFTAR PUSTAKA}

A Guide, Gender Analysis Frameworks, On Oxfam Publication

Arief budiman, 1985, Pembagian Kerja secara seksual, Gramedia Jakarta

BKKBN : Analisis Gender, Jakarta, 2002

BPS, Statistik dan Indikator Gender, 2000

Ismini, 1990, Pola Kerja dan Sumbangannya Terhadap Pendapatan Rumah Tangga Petani di Desa tamansari, Kecamatan Ampel gading Malang, Universitas Widyagama Malang

Ismini, 1999, Peranan Wanita Tani untuk Meningkatkan Pendapatan Rumah Tangga, Penelitian BBI Dikti.

Ismini, 2007, Wanita Pekerja Kondektur Bus PO Akas di Probolinggo, Fakultas Pertania Universitas widyagama Malang

Keppi S, Sugiyanto, 1987, Peranan Wanita Buruh tani di Pdesaan jawa Timur, universitas Brawijaya Malang.

Masri S., 1985., Metode Penelitian surve, LP3Es, Jakarta.

Pudjiwati S., 1983, Peranan Wanita dalam Perkembangan Masyarakat Desa, CV Rajawali Jakarta.

Wahyu Anny, Ismini, Evi N., 1998, Wanita Pekerja Pemecah Batu di Kecamatan Tumpang di Kab. Malang, Penelitian BBI DIKTI. 